\title{
Hand rim wheelchair training: Effects of intensity and duration on physical capacity
}

\author{
Sonja de Groot ${ }^{1,2^{*}}$, Jan W. van der Scheer ${ }^{2}$, Jordi A. van der Windt ${ }^{3}$, Joske Nauta ${ }^{3}$, \\ Louise J. C. van der Hijden ${ }^{3}$, Linda Luigjes ${ }^{3}$, Lucas H. V. van der Woude ${ }^{2,4}$ \\ ${ }^{1}$ Amsterdam Rehabilitation Research Center/Reade, Amsterdam, The Netherlands; ${ }^{*}$ Corresponding Author: $\underline{\text { s.d.groot@reade.nl }}$ \\ ${ }^{2}$ University of Groningen, University Medical Center Groningen, Center for Human Movement Sciences, Groningen, The Netherlands \\ ${ }^{3}$ Research Institute MOVE, Faculty of Human Movement Sciences, VU University, Amsterdam, The Netherlands \\ ${ }^{4}$ University of Groningen, University Medical Center Groningen, Center for Rehabilitation, Groningen, The Netherlands
}

Received 28 February 2013; revised 29 March 2013; accepted 10 May 2013

Copyright (C) 2013 Sonja de Groot et al. This is an open access article distributed under the Creative Commons Attribution License, which permits unrestricted use, distribution, and reproduction in any medium, provided the original work is properly cited.

\begin{abstract}
The purpose of this study was to compare the effects of intensity and duration of training on physical capacity in a 7 weeks hand rim wheelchair training in able-bodied men. Thirty-six able-bodied men participated in three groups: a 30\% heart rate reserve (HRR) $\mathbf{7 0}$ min training group ( $N=14)$, a $70 \%$ HRR 30 minutes training group $(N=13)$ and a $30 \%$ HRR 30 minutes training group $(N=9)$. All groups trained 3 times per week for 7 weeks on a treadmill. Pre and post tests on a wheelchair ergometer comprised a submaximal test at $20 \%$ and $40 \%$ of the estimated peak power output, in which submaximal heart rate, oxygen uptake and mechanical efficiency were determined. In maximal exercise tests, maximal isometric strength, sprint power, peak power output and peak oxygen uptake were measured. No significant differences were found between the training groups on submaximal and maximal parameters. It can be concluded that, in persons new to wheelchair use, seven weeks of wheelchair endurance training at an intensity of $\mathbf{3 0 \%}$ HRR for $\mathbf{3 0}$ minutes is as effective as a training at a higher intensity $(70 \%$ HRR) or with a longer duration (70 min).
\end{abstract}

Keywords: Wheelchairs; Oxygen Consumption; Work Capacity; Physical Education and Training

\section{INTRODUCTION}

During almost all activities of daily living, wheelchairdependent persons rely on their upper-body only. Because the physical strain can be very high during wheel- chair-related activities of daily living [1], upper-body strength and cardiovascular endurance are extremely importent for the independence of individuals who use manual wheelchairs [2]. The physical capacity of wheelchair-dependent individuals which is often low as a result of the disability and sedentary lifestyle [3], however, can be improved by training [2].

Regular training programs are often based on the guidelines of the American College of Sports Medicine (ACSM) recommending minimum exercise intensities of $40 \%$ of the heart rate reserve (HRR) [4]. These guidelines are initially meant for large leg muscle training and are effective in full-cyclic and more efficient upper-body exercise, such as cycling but also handcycling [5]. Van der Woude et al. [2] showed that a 70\% HRR as well as a 50\% HRR intensity hand rim wheelchair training (30 minutes, 3 times/week) were effective in improving the physical capacity of able-bodied men. However, such training intensities are deemed to lead to fatigue and pain in hand rim wheelchair propulsion at the start of inpatient rehabilitation. This might be due to the small muscle mass involved and the discontinuous movement pattern introducing high mechanical and physiological peak strains [6]. Van Drongelen and colleagues [7] showed that $39 \%$ of the persons with a spinal cord injury had shoulder musculoskeletal pain at the start of inpatient rehabilitation. They concluded that at the beginning of inpatient rehabilitation, one should be very careful to prevent overload and, therefore, should focus on a balanced training of the upper-body muscular system [7]. Furthermore, at the start of the rehabilitation process it might be difficult for patients to get motivated for highintensity exercise training at all. In that respect, low-intensity wheelchair training might be very useful in the early rehabilitation setting when the physical capacity of patients is often low [8] and musculoskeletal complaints 
occur frequently [7]. Haskell [9] was among the first to stress the importance of low-intensity exercise for rehabilitation populations and frail elderly. A previous study [10] showed that a $30 \%$ HRR intensity hand rim wheelchair training (30 minutes, 3 times/week) was also effective in improving the physical capacity in able-bodied men compared to a non-training control group. From the above-mentioned wheelchair training studies we know that all training groups (at $30 \%, 50 \%$ or $70 \%$ HRR) $[2,10]$ showed an improvement in physical capacity compared to a control group and that there were no statistical differences between the $50 \%$ and $70 \%$ HRR training groups. However, the very low $(30 \%)$ and high $(70 \%)$ intensity groups have not been compared yet. Furthermore, the effect of duration of training has not yet been investigated. Therefore, in the present study, a group was trained at a low-intensity ( $30 \%$ HRR) but the duration of this training was lengthened to 70 minutes per training session. In this way, a comparable dose (frequency $x$ duration $\times$ intensity) is achieved as the high intensity training group in the previous study of Van der Woude et al. ( $70 \%$ HRR for 30 minutes) [2]. Furthermore, the effect of duration of the training can be evaluated by comparing the results of this new training group ( 3 times per week for 70 minutes at $30 \% \mathrm{HRR}$ ) with the results of the low-intensity training group of Van den Berg and colleagues [10], with an identical frequency and intensity but a shorter duration (30 minutes).

The purpose of the present study was to investigate the effects of intensity and duration of wheelchair training on the physical capacity (maximal isometric strength, sprint power, peak aerobic capacity and submaximal performance) of able-bodied men inexperienced in wheelchair propulsion.

\section{METHODS}

\subsection{Participants}

Fourteen able-bodied men who were inexperienced in wheelchair propulsion were included in this study. Inclusion criteria were: male, 18 - 30 years of age, no engagement in sports that extensively train the upper extremities over the last year, no experience in wheelchair propulsion, and no medical contra-indications. The experiment was approved by the ethics committee of the Faculty of Human Movement Sciences, VU University Amsterdam, The Netherlands. Prior to experimentation, the participants gave their written informed consent. Characteristics of the participants are summarized in Table 1.

\subsection{Design}

A group of 14 men was trained at a low-intensity and with a long-duration (30\% HRR-70 min), and compared with previously trained and measured groups: a low-
Table 1. Mean and standard deviation (SD) of the participant characteristics for the three groups and results of the one-way ANOVA among groups at pre and post test.

\begin{tabular}{|c|c|c|c|c|}
\hline & $\begin{array}{c}30 \%-70 \text { min } \\
(N=14) \\
\text { Mean } \pm \text { SD }\end{array}$ & $\begin{array}{c}\text { 30\%-30 min } \\
(N=\mathbf{1 0}) \\
\text { Mean } \pm \text { SD }\end{array}$ & $\begin{array}{c}70 \%-30 \text { min } \\
(N=13) \\
\text { Mean } \pm \text { SD }\end{array}$ & $p$-value \\
\hline Age (yr) & $23.5 \pm 3.5$ & $22.7 \pm 2.0$ & $21.9 \pm 3.2$ & 0.41 \\
\hline Height (cm) & $180.9 \pm 10.5$ & $183.7 \pm 4.8$ & $184.2 \pm 8.3$ & 0.57 \\
\hline \multirow{2}{*}{$\begin{array}{cc}\text { Body mass } & \text { pre } \\
(\mathbf{k g}) & \text { pos }\end{array}$} & $73.0 \pm 12.5$ & $76.8 \pm 4.9$ & $71.8 \pm 6.0$ & 0.39 \\
\hline & $73.2 \pm 12.0$ & $77.0 \pm 5.1$ & $71.5 \pm 6.4$ & 0.36 \\
\hline
\end{tabular}

intensity short-duration training group (30\% HRR-30min, $N=9)$ [10] and a high-intensity short-duration training group (70\% HRR-30 min, $N=13$ ) [2]. All training groups participated in a 7-week wheelchair training, with a frequency of three times per week. The training was performed on two motor-driven treadmills (Vrije University (VU): Enraf Nonius, model 3446, Delft, The Netherlands. Reade, centre for Rehabilitation \& rheumatology (Reade): Bonte BV, model GTR 2.50, En-Bo systems, Zwolle, The Netherlands) with two standardized wheelchairs (VU: Quickie triumph, Reade: Sopur ${ }^{\circledR}$ starlight). Before and after training, participants performed an isometric strength test, sprint test, submaximal and peak exercise test on a wheelchair ergometer [2]. All post tests were identical to the pre tests in terms of speed, resistance (and thus submaximal power output settings), wheelchair ergometer settings and protocols.

\subsection{Wheelchair Ergometer Tests}

Participants performed an exercise test on a computercontrolled wheelchair ergometer, which measures forces and torques applied to the hand rims [11].

Isometric strength tests. First the maximal isometric strength test was conducted to determine the maximal force (Fiso) that the participant could exert on the hand rim. Three consecutive 5-s maximal force exertions were performed with the hands placed on top of the blocked hand rims. The effective force was averaged over the highest three seconds of each trial. The highest value of the three trials was defined as the maximal isometric strength of the person. With the results of the isometric strength test, the individual's peak power output was estimated $\left(\mathrm{PO}_{\text {peak-est } 1}\right)$ according to the equation of Janssen et al. [12]:

$$
\mathrm{PO}_{\text {peak-est } 1}\left(\mathrm{~W} \cdot \mathrm{kg}^{-1}\right)=0.34 \times F_{\text {iso }}\left(\mathrm{N} \cdot \mathrm{kg}^{-1}\right)-0.02
$$

Sprint test. On completion of the isometric strength test participants rested for 8 minutes. Then they performed a warming up for 3 minutes, and rested again 3 minutes. Before starting the sprint test, estimated sprint power $\left(P 30_{\text {est }}\right)$ was determined by using the equation between Fiso and the sprint power [12] to be able to set 
an individualized resistance level, i.e.:

$$
P 30_{\text {est }}\left(\mathrm{W} \cdot \mathrm{kg}^{-1}\right)=0.51 \times F_{\text {iso }}\left(\mathrm{N} \cdot \mathrm{kg}^{-1}\right)-0.18
$$

The resisting force $\left(F_{r}\right)$ was calculated from $P 30_{\text {est }}$ and an average velocity that had to stay below the $2 \mathrm{~m} \cdot \mathrm{s}^{-1}$ to prevent coordination problems [12]:

$$
F_{r}\left(\mathrm{~N} \cdot \mathrm{kg}^{-1}\right)=P 30_{\text {est }} \cdot \mathrm{V}^{-1} \cdot \mathrm{W}^{-1}
$$

The sprint test started at zero velocity and then the participants performed an all-out sprint for $30 \mathrm{~s}$. Sprint power (P30) was defined as the mean power output during the 30-s test period (sum of right and left wheel).

Submaximal exercise test. Following a 10 minute resting period the submaximal exercise test was performed, which consisted of two blocks of three minutes wheelchair propulsion with an intensity of respectively $20 \%$ and $40 \%$ of the estimated POpeak [2] and a velocity of $1.39 \mathrm{~m} \cdot \mathrm{s}^{-1}$. The estimated POpeak was calculated [12] as follows:

$$
\mathrm{PO}_{\text {peak-est }}-\mathrm{II}\left(\mathrm{W} \cdot \mathrm{kg}^{-1}\right)=0.67 \times P 30\left(\mathrm{~W} \cdot \mathrm{kg}^{-1}\right)+0.11
$$

During the test, oxygen uptake $\left(\mathrm{VO}_{2}\right)$ was measured breath-by-breath with a computerized gas analyzing system (Oxycon Alpha, Jaeger, Bunnik, The Netherlands), which was calibrated before each test. Furthermore, heart rate (HR) recordings were made with a sporttester (Polar sport tester, Polar electro Inx, Kemple, Finland). Average values over the third minute of each exercise block were determined $\left(\mathrm{VO}_{2} 20, \mathrm{VO}_{2} 40, \mathrm{HR} 20, \mathrm{HR} 40\right)$. During the last $15 \mathrm{~s}$ of each block, ergometer data (torque (M) and angular velocity $(\omega)$ ) were recorded to calculate the power output (PO) [2]:

$$
\mathrm{PO}=M \cdot \omega(\mathrm{W})
$$

Energy expenditure (En) was calculated with the $\mathrm{VO}_{2}$ and respiratory exchange ratio (RER) values [13] and subsequently, the gross mechanical efficiency (ME20 and ME40) was calculated with the equation:

$$
\mathrm{ME}=\mathrm{PO} \cdot \mathrm{En}^{-1} \times 100 \%
$$

Peak exercise test. Immediately after the submaximal exercise blocks the peak exercise test started with a workload of $20 \%$ estimated POpeak. The intensity increased every minute with $10 \%$ estimated POpeak, with a constant velocity of $1.39 \mathrm{~m} \cdot \mathrm{s}^{-1}$, until exhaustion. The absolute PO and speed for each individual were identical at the pre and post tests. The $\mathrm{VO}_{2}$ values obtained during the last $30 \mathrm{~s}$ of the peak exercise test were averaged and considered as peak value $\left(\mathrm{VO}_{2}\right.$ peak). Furthermore, the power output was determined as the average of the last $15 \mathrm{~s}$ of a block. POpeak was defined as the highest PO achieved during the test. Peak work capacity was operationally defined as volitional fatigue, limiting symptoms, or the point at which increasing the workload failed to provoke further increased oxygen uptake, and evidently the inability to maintain the required speed.

\subsection{Training}

Participants received a 7-week training on a treadmill, three times per week at $30 \% \mathrm{HRR}$ for $70 \mathrm{~min}$, and were compared to groups that trained at $30 \%$ HRR for $30 \mathrm{~min}$ or $70 \% \mathrm{HRR}$ for $30 \mathrm{~min}$ per session $[2,10]$. Before the first training session a drag test was performed to determine rolling resistance and internal friction of the wheelchair. The required HR during the training $\left(\mathrm{HR}_{\text {training }}\right)$ was determined according to the formula of Karvonen et al. [14] by using the peak heart rate (HRpeak) and HR during rest, both measured during the pre test. The required PO, which elicited an intensity of $30 \%$, was determined by the linear relation between $\mathrm{HR}$ and PO, measured during the peak aerobic exercise test pre training [2]. When needed, the resistance was increased by an additional pulley force [2] (Figure 1).

The training stimuli varied according to three different patterns of the training intensity [2] (Figure2). The patterns were designed such that the mean product of resisting force and velocity resembled a heart rate reponse of $30 \%$ HRR over the session. Every three minutes the velocity or resistance force was changed. In the velocity training, the resistance force was kept constant over the training session, while the velocity was changed. In the resistance training, the velocity was kept constant over the training session at $1.39 \mathrm{~m} \cdot \mathrm{s}^{-1}$, while the resistance force was changed. The HR was closely monitored and recorded during the training to make sure that the proper training intensity was maintained as the training progressed.

\subsection{Statistics}

To evaluate possible differences between the three training groups regarding participant characteristic (age, height, body mass) or physical capacity (Fiso, P30, POpeak, $\mathrm{VO}_{2}$ peak, $\mathrm{VO}_{2} 20, \mathrm{VO}_{2} 40, \mathrm{HR} 20, \mathrm{HR} 40, \mathrm{ME} 20$,

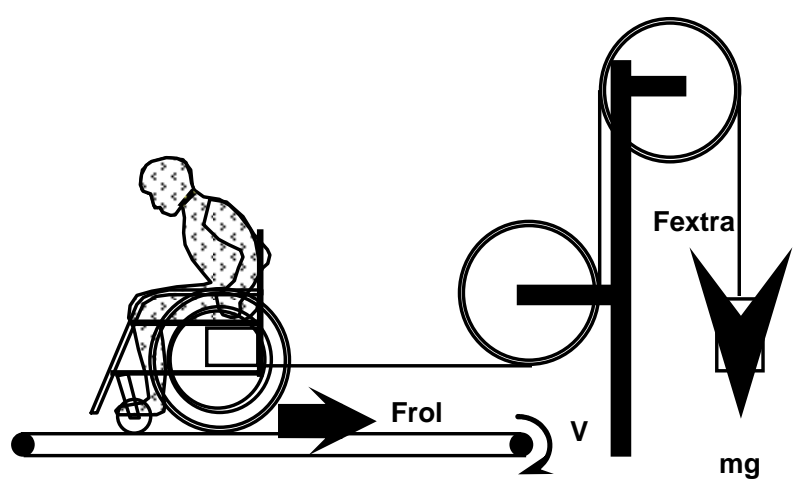

Figure 1. To impose the desired power output during the training a pulley-system attaches to the instrumented wheelchair on the treadmill. 

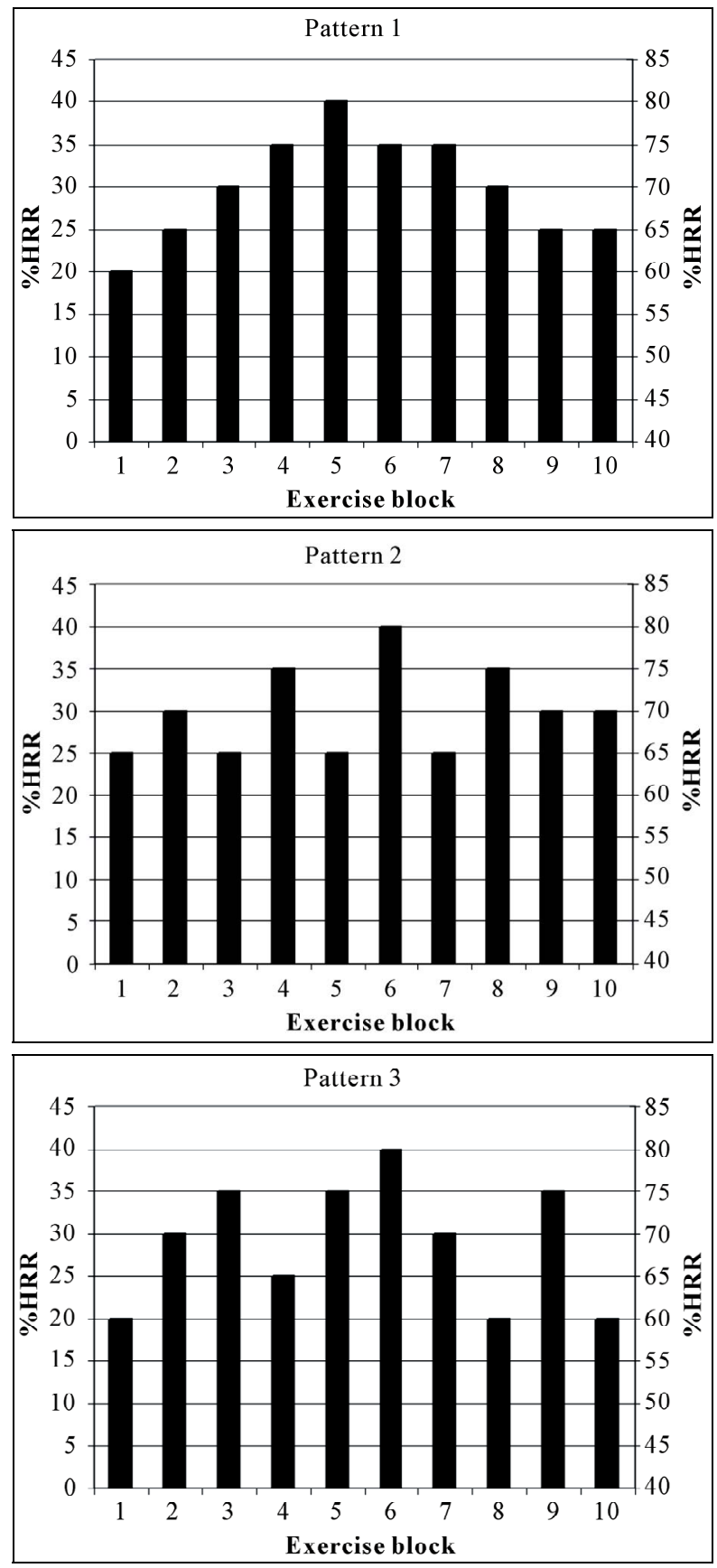

Figure 2. Representation of temporal patterns of the training sessions for the low-intensity (30\% HRR, left y-axis) and norm-intensity (70\% HRR, right y-axis) training groups.

ME40) at the start of the study a one-way ANOVA was executed.

Effects of training on physical capacity were analyzed using a repeated measures ANOVA for each of the parameters individually. The between-subject factor was group (30\% HRR for $70 \mathrm{~min}, 30 \% \mathrm{HRR}$ for $30 \mathrm{~min}, 70 \%$ HRR for $30 \mathrm{~min}$ ), the within-subject factor was test (prepost). If necessary, the outcomes of the pre test were added as a covariate (ANCOVA) to adjust for significant differences between the groups at baseline. Interaction of the within and between variables (group $\times$ time) was of special interest and considered significant when $p<0.05$. To identify the potential differences found with the repeated measures ANOVA, post hoc repeated measures ANOVAs were performed with a Bonferroni correction of $p<0.0167$ (0.05/3 tests).

\section{RESULTS}

No differences in participant characteristics were found between the groups at the pre test (Table 1), however, significant differences were found between the groups for Fiso, POpeak, $\mathrm{VO}_{2}$ peak, ME20 and ME40 (Table 2). Analysis of the HRR data obtained during the training revealed that the average training intensity was $33 \%$ HRR for the 30\% HRR-70 min group, 28.8\% HRR for the 30\%-30 min group and 67\% HRR for the $70 \%$ HRR-30 min group. All participants completed all training sessions.

\subsection{Isometric Strength}

Fiso showed an increase in all training groups $(30 \%$ HRR-70 min: $+55 \mathrm{~N}$; 30\% HRR-30 min: $+29 \mathrm{~N} ; 70 \%$ HRR-30 min: $+41 \mathrm{~N}$ ), but this increase was not significantly different between the groups (interaction term group time: $p=0.56$; Table 2 ).

\subsection{Sprint Power}

Changes in $P 30$ over time were not significantly different between the training groups (interaction term group time: $p=0.28$ ). The $30 \%$ HRR-70 min group showed a significant increase from pre to post tests in $P 30$ of $30 \mathrm{~W}$, the $30 \%$ HRR-30 min group of $35 \mathrm{~W}$ and the 70\% HHR-30 min group of $22 \mathrm{~W}$ (Table 2, Figure 3).

\subsection{Peak Exercise Test}

All training groups showed an increase in POpeak and this improvement was not significantly different between the groups (interaction term group $*$ time: $p=0.27$, Table 2). The increase in POpeak varied between $23-29 \mathrm{~W}$ (Table 2, Figure 3). $\mathrm{VO}_{2}$ peak significantly improved between pre and post tests, but appeared not different among the training groups (interaction term group $*$ time: $p=0.25$, Table 2, Figure 3).

\subsection{Submaximal Exercise}

No significant differences were found between the three training groups in the submaximal parameters $\mathrm{VO}_{2}$, mechanical efficiency and heart rate (Table 3, Figure 3). All groups showed a comparable decrease in submaximal $\mathrm{VO}_{2}$ and heart rate and an increase in mechanical effi- 
Table 2. Mean and SD for isometric strength (Fiso), sprint power (P30), peak power output (POpeak), peak oxygen uptake $\left(\mathrm{VO}_{2}\right.$ peak), and peak heart rate (HRpeak) for the three groups pre and post training and the results of the repeated measurement ANOVA.

\begin{tabular}{|c|c|c|c|c|c|c|c|c|c|}
\hline & & $\begin{array}{l}30 \%-70 \text { min } \\
(\text { mean } \pm \text { SD) }\end{array}$ & $\mathbf{N}$ & $\begin{array}{l}30 \%-30 \text { min } \\
(\text { mean } \pm \text { SD) }\end{array}$ & $\mathbf{N}$ & $\begin{array}{r}70 \%-30 \text { min } \\
(\text { mean } \pm \text { SD) }\end{array}$ & $\mathbf{N}$ & $\begin{array}{l}\text { Interaction } \\
\text { group*time }\end{array}$ & Test \\
\hline \multirow{2}{*}{ Fiso $(\mathrm{N})^{*}$} & pre & $391.0 \pm 92.9$ & \multirow{2}{*}{14} & $475.8 \pm 84.3$ & \multirow{2}{*}{9} & $243.5 \pm 75.1$ & \multirow{2}{*}{13} & \multirow{2}{*}{0.56} & \multirow{2}{*}{0.78} \\
\hline & post & $446.0 \pm 150.9$ & & $494.8 \pm 109.0$ & & $285.8 \pm 84.7$ & & & \\
\hline \multirow{2}{*}{ P30 (W) } & pre & $97.0 \pm 18.2$ & \multirow{2}{*}{14} & $114.0 \pm 33.5$ & \multirow{2}{*}{9} & $102.7 \pm 18.9$ & \multirow{2}{*}{13} & \multirow{2}{*}{0.28} & \multirow{2}{*}{$<0.001$} \\
\hline & post & $126.7 \pm 27.5$ & & $148.7 \pm 29.2$ & & $124.8 \pm 27.8$ & & & \\
\hline \multirow{2}{*}{$\operatorname{POpeak}(\mathrm{W})^{+}$} & pre & $43.7 \pm 11.9$ & \multirow{2}{*}{14} & $56.5 \pm 10.7$ & \multirow{2}{*}{9} & $52.9 \pm 10.2$ & \multirow{2}{*}{13} & \multirow{2}{*}{0.27} & \multirow{2}{*}{$<0.001$} \\
\hline & post & $66.7 \pm 11.2$ & & $75.6 \pm 12.6$ & & $79.0 \pm 15.4$ & & & \\
\hline \multirow{2}{*}{$\mathrm{VO}_{2}$ peak $(1 / \mathrm{min})^{\#}$} & pre & $1.75 \pm 0.27$ & \multirow{2}{*}{14} & $2.13 \pm 0.32$ & \multirow{2}{*}{9} & $1.80 \pm 0.30$ & \multirow{2}{*}{13} & \multirow{2}{*}{0.25} & \multirow{2}{*}{0.014} \\
\hline & post & $1.95 \pm 0.33$ & & $2.09 \pm 0.28$ & & $2.00 \pm 0.28$ & & & \\
\hline \multirow{2}{*}{ HRpeak } & pre & $182 \pm 12$ & \multirow{2}{*}{13} & $171 \pm 17$ & \multirow{2}{*}{9} & $175 \pm 13$ & \multirow{2}{*}{13} & \multirow{2}{*}{0.19} & \multirow{2}{*}{0.38} \\
\hline & post & $176 \pm 17$ & & $171 \pm 21$ & & $176 \pm 12$ & & & \\
\hline
\end{tabular}

${ }^{*} 70 \%$ HRR-30 min showed a significantly lower Fiso than the $30 \% \mathrm{HRR}$ training groups at the pre-test; ${ }^{+} 30 \%$ HRR-70 min showed a significantly lower POpeak than the $30 \%$ HRR-30 min training group at the pre-test; ${ }^{*} 30 \% \mathrm{HRR}-30 \mathrm{~min}$ showed a significantly lower $\mathrm{VO}_{2}$ peak than the $30 \% \mathrm{HHR}_{-30}$ min and $70 \%$ HRR-30 min training groups at the pre-test.

Table 3. Results of the submaximal tests: mean and SD of oxygen uptake $\left(\mathrm{VO}_{2}\right)$, mechanical efficiency (ME) and heart rate (HR) at $20 \%$ estimated POpeak (20) and at $40 \%$ estimated POpeak (40) for the three groups pre and post training, and the results of the repeated measurements ANOVA.

\begin{tabular}{|c|c|c|c|c|c|c|c|c|c|}
\hline & & $30 \%-70 \mathrm{~min}$ & $\mathbf{N}$ & $30 \%-30 \mathrm{~min}$ & $\mathbf{N}$ & 70\%-30 min & $\mathbf{N}$ & Interaction group*time & Test \\
\hline \multirow{2}{*}{$\mathrm{VO}_{2} 20(1 / \mathrm{min})$} & pre & & \multirow{2}{*}{14} & $0.86 \pm 0.17$ & \multirow{2}{*}{9} & $0.79 \pm 0.14$ & \multirow{2}{*}{13} & \multirow{2}{*}{0.44} & \multirow{2}{*}{$<0.001$} \\
\hline & post & $0.68 \pm 0.10$ & & $0.69 \pm 0.12$ & & $0.67 \pm 0.08$ & & & \\
\hline \multirow{2}{*}{$\mathrm{VO}_{2} 40(1 / \mathrm{min})$} & pre & $1.17 \pm 0.23$ & \multirow{2}{*}{14} & $1.17 \pm 0.21$ & \multirow{2}{*}{9} & $1.15 \pm 0.20$ & \multirow{2}{*}{13} & \multirow{2}{*}{0.43} & \multirow{2}{*}{$<0.001$} \\
\hline & post & $0.92 \pm 0.14$ & & $0.95 \pm 0.11$ & & $0.98 \pm 0.13$ & & & \\
\hline \multirow{2}{*}{$\operatorname{ME20}(\%)^{*}$} & pre & $4.32 \pm 1.27$ & \multirow{2}{*}{14} & $5.36 \pm 0.99$ & \multirow{2}{*}{9} & $6.25 \pm 1.59$ & \multirow{2}{*}{13} & \multirow{2}{*}{0.30} & \multirow{2}{*}{$<0.001$} \\
\hline & post & $5.65 \pm 0.82$ & & $6.27 \pm 0.98$ & & $7.36 \pm 1.60$ & & & \\
\hline \multirow{2}{*}{$\operatorname{ME40}(\%)^{*}$} & pre & $6.41 \pm 1.17$ & \multirow{2}{*}{14} & $7.25 \pm 0.88$ & \multirow{2}{*}{9} & $8.33 \pm 1.80$ & \multirow{2}{*}{13} & \multirow{2}{*}{0.88} & \multirow{2}{*}{$<0.001$} \\
\hline & post & $8.32 \pm 0.89$ & & $9.00 \pm 1.61$ & & $9.85 \pm 1.54$ & & & \\
\hline \multirow{2}{*}{ HR20 (bpm) } & pre & $125 \pm 22$ & \multirow{2}{*}{14} & $111 \pm 19$ & \multirow{2}{*}{9} & $111 \pm 14$ & \multirow{2}{*}{13} & \multirow{2}{*}{0.46} & \multirow{2}{*}{$<0.001$} \\
\hline & post & $105 \pm 13$ & & $97 \pm 16$ & & $98 \pm 10$ & & & \\
\hline \multirow{2}{*}{ HR40 (bpm) } & pre & $143 \pm 25$ & \multirow{2}{*}{14} & $127 \pm 22$ & \multirow{2}{*}{9} & $132 \pm 17$ & \multirow{2}{*}{13} & \multirow{2}{*}{0.32} & \multirow{2}{*}{$<0.001$} \\
\hline & post & $114 \pm 16$ & & $106 \pm 16$ & & $112 \pm 12$ & & & \\
\hline
\end{tabular}

*Significant difference between the $30 \%$ for $70 \mathrm{~min}$ and $70 \%$ for $30 \mathrm{~min}$ training groups at the pre test.

ciency from pre to post tests.

\section{DISCUSSION}

No significant differences in changes in maximal and submaximal physical capacity parameters were found between the three training groups. This indicates that, in persons new to wheelchair use, a $30 \mathrm{~min}$ low-intensity training induces the same effects as training with a longer duration (70 min per session) or at a higher intensity (70\% HRR). The intensity of training in the $30 \%$ HRR groups was much lower than recommended by the guidelines of the ACSM [4], which state a minimal training intensity of $40 \% \mathrm{HRR}$ to improve the physical capacity.

Physiological adaptations to exercise are dependent on the mass of muscle involved. Aerobic exercise with large muscle groups leads to central and peripheral adaptations while exercise with small muscle groups may only lead to peripheral adaptations [15]. Wheelchair exercise may lead to peripheral adaptations specific to the trained arm muscles but central adaptations will be less pronounced due to the lower blood flow and cardiac output requirements during arm exercise. However, efficiency can be improved due to peripheral adaptations, such as for example capillary density, or changes in propulsion technique due to practice. The effect of the duration of training sessions, and thus of practice time, was studied by 

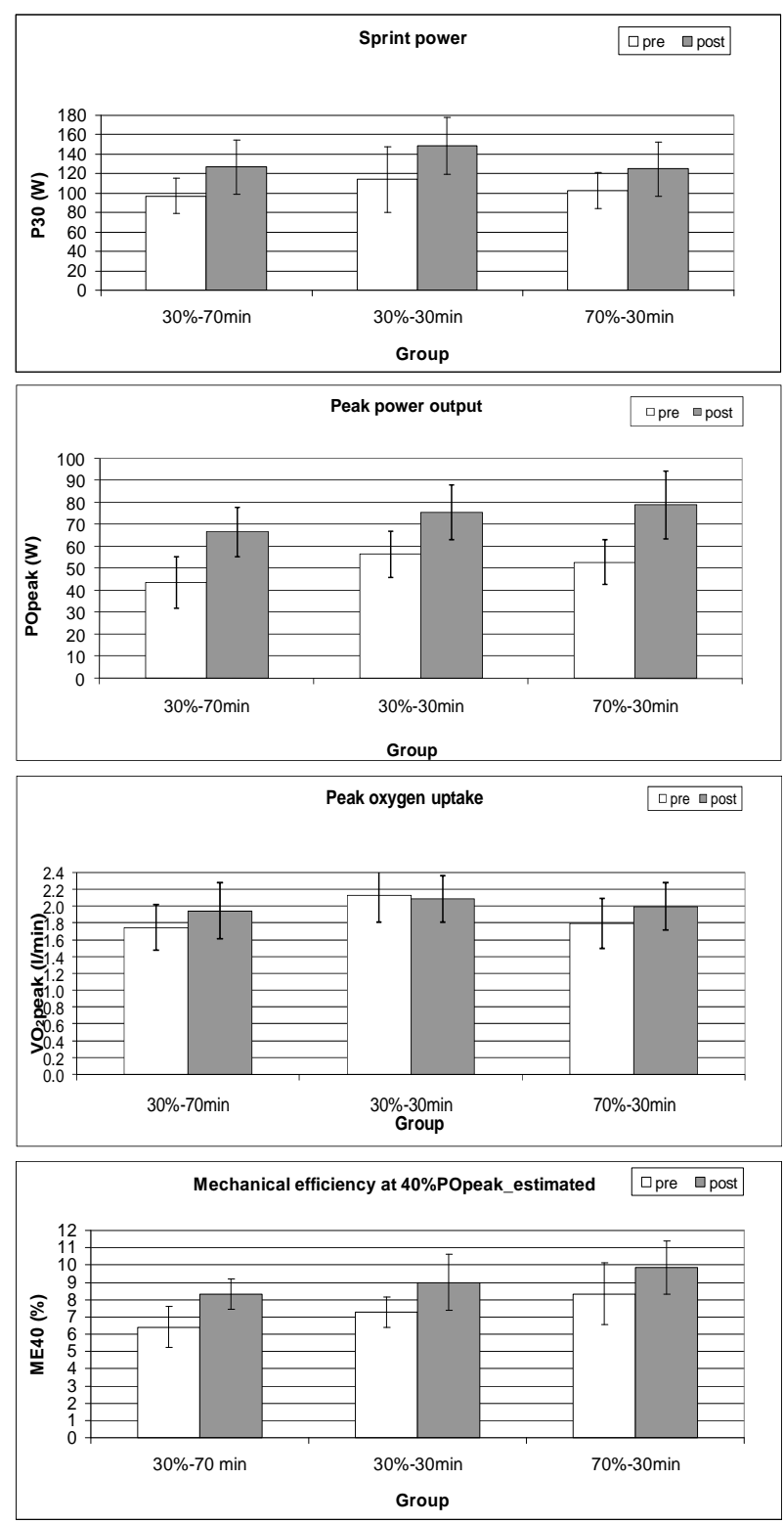

Figure 3. Mean and SD of the pre and post test values for sprint power (P30), peak power output (POpeak), peak oxygen uptake $\left(\mathrm{VO}_{2}\right.$ peak) and the mechanical efficiency (ME40) for the low-intensity, long-duration training group (30\%-70 $\mathrm{min})$, the low-intensity, short-duration training group (30\%-30 min) and norm-intensity, short-duration training group (70\%-30 $\min )$.

training a group at an intensity of $30 \%$ HRR but for 70 min per session, which has not been done before. The extra training time of $40 \mathrm{~min} / \mathrm{session}$ did not lead to more improvement in physical capacity. However, a minimum amount of practice time seems to be important. With more practice time, participants might be able to improve the propulsion technique more and subsequently their metabolic cost. When comparing results from previous wheelchair training studies, an increase in practice time from $12 \mathrm{~min}$ [16] to $84 \mathrm{~min} \mathrm{[17]} \mathrm{to} 630 \mathrm{~min}(30 \%$ or
$70 \%$ HRR-30 $\min [18]$ ) to $1470 \mathrm{~min}(30 \% \mathrm{HRR}-70 \mathrm{~min})$ showed larger changes in $\mathrm{ME}$ (from $+0.08 \%$ to $+0.95 \%$ to $+1.8 \%$ to $+1.9 \%$, respectively), with most change in the beginning of a practice period (between 12 - 630 $\mathrm{min})$. This increase in ME in the above-mentioned studies was accompanied by an improvement in propulsion technique, i.e. a lower push frequency and subsequently increase in work per cycle. However, the study groups were tested approximately at the same power output (23 $27 \mathrm{~W}$ ) but practiced at a different power and intensity so no strong conclusion can be drawn regarding the effect of practice time on physical capacity.

Our previous study showed that the 70\% HRR-30 min group showed a significant improvement in $\mathrm{VO}_{2}$ peak compared to a control group [2]. However, the 50\% HRR group [2] and 30\% HRR group [10] did not show a significant increase in $\mathrm{VO}_{2}$ peak compared to a control group. In contrast, previous studies found a significant increase in $\mathrm{VO}_{2}$ peak in low, moderate or high intensity training groups in elderly [19], patients with chronic heart failure [20] and cancer survivors [21]. One of the differences between these studies and our study is the type of training, i.e. lower-body (large muscle mass) versus upper-body (small muscle mass) exercise. From the above-mentioned results, it seems that for an increase in $\mathrm{VO}_{2}$ peak high-intensity upper-body exercise or exercise with a larger muscle mass is necessary.

Little is known about the benefit of low-intensity training in healthy as well as in disabled participants. Low-intensity lower-body aerobic exercise training $(25 \%$ - $35 \%$ or $40 \%-50 \%$ HRR, $3 \times 14-32 \mathrm{~min} /$ per week for 10 weeks) performed by cancer survivors revealed that both training groups did show a significant decrease in body fat, an improvement in aerobic capacity and in quality of life compared to the non-training control group [21]. Another study [19] found that cycling exercise at a low intensity $(30 \%-45 \%$ HRR, $3 \times 25$ min per week for 9 weeks) is an adequate training stimulus in older individuals and produces changes in peak oxygen uptake that are comparable to those elicited by high-intensity $(60 \%$ $75 \% \mathrm{HRR}$ ) training. Similar increases in $\mathrm{VO}_{2}$ peak were found between low (30\% HRR) and high (70\% HRR) walking exercise intervention groups in postpartum women [22]. The results of these studies and our study strongly indicate that a low-intensity training might be very useful for wheelchair users in early rehabilitation. Even in our fit able-bodied participants, yet untrained with respect to upper-body cyclic wheelchair exercise, favorable changes in physical capacity were found. These changes are probably due to peripheral physiological adaptations and changes in propulsion technique, which also occur at a low intensity and short duration. Since the results of this low-intensity wheelchair training were promising, we will perform a future study including wheelchair users with a spinal cord injury and will inves- 
tigate the effect of low-intensity wheelchair training (30\% HRR for $30 \mathrm{~min}$ ) on overuse problems, propulsion technique, physical capacity, active lifestyle and health [23].

\section{Limitations}

Since the 70\% HRR-30 min and 30\% HRR-30 min training groups participated in earlier studies [2,10], it was not possible to randomize the total group of participants. Although the same inclusion criteria were used, some physical capacity parameters showed a significant difference between the three groups at the pre test. However, we statistically corrected for pre test differences between the groups.

Because there was no knowledge available regarding the effect of such a low-intensity wheelchair training on the physical capacity, the present study made a start by including able-bodied men inexperienced in wheelchair propulsion. Relative trends may carefully be generalized to novice wheelchair users in early rehabilitation. Indeed our study population as such they partly mimic novice wheelchair users in early rehabilitation. The absolute values cannot be generalized automatically to wheelchair users with a disability.

\section{CONCLUSION}

The present study showed that a low-intensity wheelchair training at $30 \% \mathrm{HRR}$ and a duration of 30 or $70 \mathrm{~min}$ were as effective in improving the physical capacity as a regular intensity training $(70 \% \mathrm{HHR}, 30 \mathrm{~min})$ in ablebodied men without wheelchair experience. An improvement in sprint power, peak power output, submaximal $\mathrm{VO}_{2}, \mathrm{HR}$ and gross mechanical efficiency was found in all training groups. A longer duration of the training sessions (from 30 to $70 \mathrm{~min}$ ) did not result in more improvement in the physical capacity.

\section{ACKNOWLEDGEMENTS}

The Open Access publication of this paper was funded by the Netherlands Organization for Scientific Research (NWO).

\section{REFERENCES}

[1] Janssen, T.W., van Oers, C.A., Veeger, H.E., Hollander, A.P., van der Woude, L.H. and Rozendal, R.H. (1994) Relationship between physical strain during standardised ADL tasks and physical capacity in men with spinal cord injuries. Paraplegia, 32, 844-859. doi:10.1038/sc.1994.131

[2] van der Woude, L.H., van Croonenborg, J.J., Wolff, I., Dallmeijer, A.J. and Hollander, A.P. (1999) Physical work capacity after 7 wk of wheelchair training: Effect of intensity in able-bodied subjects. Medicine \& Science in Sports \& Exercise, 31, 331-341. doi:10.1097/00005768-199902000-00018

[3] Dallmeijer, A.J., Hopman, M.T., van As, H.H. and van der Woude, L.H. (1996) Physical capacity and physical strain in persons with tetraplegia; The role of sport activity. Spinal Cord, 34, 729-735. doi:10.1038/sc.1996.133

[4] Garber, C.E., Blissmer, B., Deschenes, M.R., Franklin, B.A., Lamonte, M.J., Lee, I.M., et al. (2011) American College of Sports Medicine position stand. Quantity and quality of exercise for developing and maintaining cardiorespiratory, musculoskeletal and neuromotor fitness in apparently healthy adults: Guidance for prescribing exercise. Medicine \& Science in Sports \& Exercise, 43, 13341359. doi:10.1249/MSS.0b013e318213fefb

[5] Valent, L.J., Dallmeijer, A.J., Houdijk, H., Slootman, H.J., Post, M. W. and Van Der Woude, L.H. (2008) Influence of hand cycling on physical capacity in the rehabilitation of persons with a spinal cord injury: A longitudinal cohort study. Journal of Rehabilitation Medicine, 89, 1016-1022.

[6] van der Woude, L., Veeger, H.E.J., Dallmeijer, A.J., Janssen, T.W. and Rozendaal, L.A. (2001) Biomechanics and physiology in active manual wheelchair propulsion. $\mathrm{Me}$ dical Engineering \& Physics, 23, 713-733.

doi:10.1016/S1350-4533(01)00083-2

[7] van Drongelen S., de Groot S., Veeger, H.E., Angenot, E.L., Dallmeijer, A.J., Post, M.W., et al. (2006) Upper extremity musculoskeletal pain during and after rehabilitation in wheelchair-using persons with a spinal cord injury. Spinal Cord, 44, 152-159. doi:10.1038/sj.sc.3101826

[8] Haisma, J.A., Bussmann, J.B., Stam, H.J., Sluis, T.A., Bergen, M.P., Dallmeijer, A.J., et al. (2006) Changes in physical capacity during and after inpatient rehabilitation in subjects with a spinal cord injury. Archives of Physical Medicine and Rehabilitation, 87, 741-748. doi:10.1016/j.apmr.2006.02.032

[9] Haskell, W.L. (1994) J.B. Wolffe Memorial Lecture. Health consequences of physical activity: Understanding and challenges regarding dose-response. Medicine \& Science in Sports \& Exercise, 26, 649-660. doi:10.1249/00005768-199406000-00001

[10] Van Den Berg, R., De Groot, S., Swart, K.M. and van der Woude, L.H. (2010) Physical capacity after 7 weeks of low-intensity wheelchair training. Disability and Rehabilitation, 32, 1717-1721. doi:10.3109/09638281003649961

[11] Niesing, R., Eijskoot, F., Kranse, R., den Ouden, A.H., Storm, J., Veeger, H.E., et al. (1990) Computer-controlled wheelchair ergometer. Medical \& Biological Engineering \& Computing, 28, 329-238. doi:10.1007/BF02446151

[12] Janssen, T.W., van Oers, C.A., Hollander, A.P., Veeger, H.E. and van der Woude, L.H. (1993) Isometric strength, sprint power and aerobic power in individuals with a spinal cord injury. Medicine \& Science in Sports \& Exercise, 25, 863-870. doi:10.1249/00005768-199307000-00016

[13] Garby, L. and Astrup, A. (1987) The relationship between the respiratory quotient and the energy equivalent of oxygen during simultaneous glucose and lipid oxidation and lipogenesis. Acta Physiologica Scandinavica, 129, 443-444. 
[14] Karvonen, M., Kentala, E. and Mustala, O. (1957) The effects of training on heart rate. A longitudinal study. Annals of Medicine and Experimental Biology Fenn, 35, 307-315.

[15] Frontera, W., Dawson, D. and Slovik, D. (2006) Exercise in rehabilitation medicine. 2nd Edition, Human Kinetics Publishers, Champaign.

[16] De Groot, S., Veeger, H.E.J., Hollander, A.P. and van der Woude, L.H.V. (2003) Adaptations in physiology and propulsion techniques during the initial phase of learning manual wheelchair propulsion. Archives of Physical Medicine and Rehabilitation, 82, 504-510. doi:10.1097/01.PHM.0000069941.77921.AA

[17] De Groot, S., Veeger, H.E.J., Hollander, A.P. and van der Woude, L.H. (2002) Wheelchair propulsion technique and mechanical efficiency after 3 wk of practice. Medicine \& Science in Sports \& Exercise, 34, 756-766. doi:10.1097/00005768-200205000-00005

[18] Dallmeijer, A.J., van der Woude, L.H.V. and Pathuis, C.S. (1999) Adaptations in wheelchair propulsion technique after training in able-bodied subjects. In: van der Woude, L.H.V., Hopman, M.T.E. and van Kemenade, C.H., Eds., Biomedical Aspects of Manual Wheelchair Propulsion IOS Press, Amsterdam, 224-226.

[19] Badenhop, D.T., Cleary, P.A., Schaal, S.F., Fox, E.L. and Bartels, R.L. (1983) Physiological adjustments to higher- or lower-intensity exercise in elders. Medicine \& Science in Sports \& Exercise, 15, 496-502.

doi:10.1249/00005768-198315060-00010

[20] Belardinelli, R., Capestro, F., Misiani, A., Scipione, P. and Georgiou, D. (2006) Moderate exercise training improves functional capacity, quality of life and endothelium-dependent vasodilation in chronic heart failure patients with implantable cardioverter defibrillators and cardiac resynchronization therapy. European Journal of Cardiovascular Prevention \& Rehabilitation, 13, 818-825. doi:10.1097/01.hjr.0000230104.93771.7d

[21] Burnham, T.R. and Wilcox, A. (2002) Effects of exercise on physiological and psychological variables in cancer survivors. Medicine \& Science in Sports \& Exercise, 34, 1863-1867. doi:10.1097/00005768-200212000-00001

[22] Davenport, M.H., Giroux, I., Sopper, M.M. and Mottola, M.F. (2011) Postpartum exercise regardless of intensity improves chronic disease risk factors. Medicine \& Science in Sports \& Exercise, 43, 951-958. doi:10.1249/MSS.0b013e3182051155

[23] van der Scheer, J.W., de Groot, S., Postema, K., Veeger, D.H. and van der Woude, L.H. (2012) Design of a randomized-controlled trial on low-intensity aerobic wheelchair exercise for inactive persons with chronic spinal cord injury. Disability and Rehabilitation. doi:10.3109/09638288.2012.709301 